\title{
Logical-probabilistic and simulation modeling as a toolkit for complex analysis and risk management of a cargo port
}

\author{
I.O. Bondareva ${ }^{1, *}$, M.V. Shendo ${ }^{1}$, T.V. Luneva ${ }^{1}$, and A.A. Khanova ${ }^{1}$ \\ ${ }^{1}$ Astrakhan State Technical University, 16, Tatischeva st., Astrakhan, 414056, Russia
}

\begin{abstract}
The paper presents a structural model of the risk of failure to achieve the strategic goal of a cargo port, supplemented by several levels of consideration. The model of scenarios of all existing significant risks is developed. The hybrid logical-probabilistic model, the cascade logicalprobabilistic model and the multi-level cascade hybrid LP-model of the risk of failure to achieve the main strategic goal of the port are proposed. The main idea is to link together the technology of formalizing risks using the constructed logical and probabilistic models and simulation modeling, the interpretation of the results of which is possible using LP-models and scenarios. The proposed models allow to carry out a comprehensive analysis of the risk of failure to achieve the strategic goal of a cargo port based on the scenario formalization of risks of various management levels, as well as to simplify the process of interpreting the results of simulation modeling taking into account external factors of influence. Complex using of all this models allows to develop timely informed management decisions.
\end{abstract}

\section{Introduction}

The modern transport logistics market is a competitive environment, the effective management of which requires the introduction of new tools and methods. Such methods are based on the use of advanced information and communication technologies based on a science-intensive component and allowing to support the adoption of informed management decisions. That is why, as the main reference point, it is necessary to consider the possibility of analyzing and assessing risk events and situations that arise in the process of functioning of enterprises in this area, including cargo ports. This is necessary to predict and assess the likelihood of undesirable events, as well as their further prevention. From management, the most interesting is a comprehensive multi-level analysis of the risks of failure to achieve the goals set by the port, including the main strategic goal of the company. The complexity of the analysis consists in considering the activities of the organization not only from the point of view of economic efficiency but also includes the possibility of multilateral analysis with a focus on the interests and characteristics of all parties involved in this process.

\footnotetext{
"Corresponding author: i.o.bondareva@gmail.com
} 


\section{Materials and methods}

Figure 1 shows a tree of cargo port goals, including factors for assessing their achievement and allowing to formulate the interdependence of cargo port risks considered as a failure to achieve port goals. The most significant goals were identified, the degree of influence of which on the main strategic goal "Increasing the competitiveness of the cargo port" is the greatest.

The technology of assessing and analyzing the risk of failure to solve the complex problem "Increasing the competitiveness of the cargo port" is proposed. For this task, a hybrid LP risk model is used (Figure 2), which combines risk scenarios for subjects and objects, since external and internal subjects are of certain interest in this work. Failure to achieve the strategic goal of SGccp depends on the subjects of Sccp (S1, S2, S3, .., S5) and objects goals of Gccp (GN1, GN2, ..., GN4), detailing the main goal - a complex problem. Thus, more detailed work with the tree of cargo port goals is carried out to build a logical probable (LP) model of the risk of failure to achieve the main strategic goal of the cargo port. The subjects determine who solves the posed problem, and the objects determine which smaller goals are associated with the SG problem. From the implementation of the management function of the cargo port and based on the presence of one or another degree of involvement, as well as interest in solving the indicated problem, we will single out the following subjects: S1 - port management, S2 - port clients, S3 - local government, S4 - population (not the clients of the port), S5 - the employees of the port. The subjects' failure events are represented as the L-addition of the events "lack of desire" $\mathrm{Wj}$ and "lack of opportunities" $\mathrm{Oj}$.

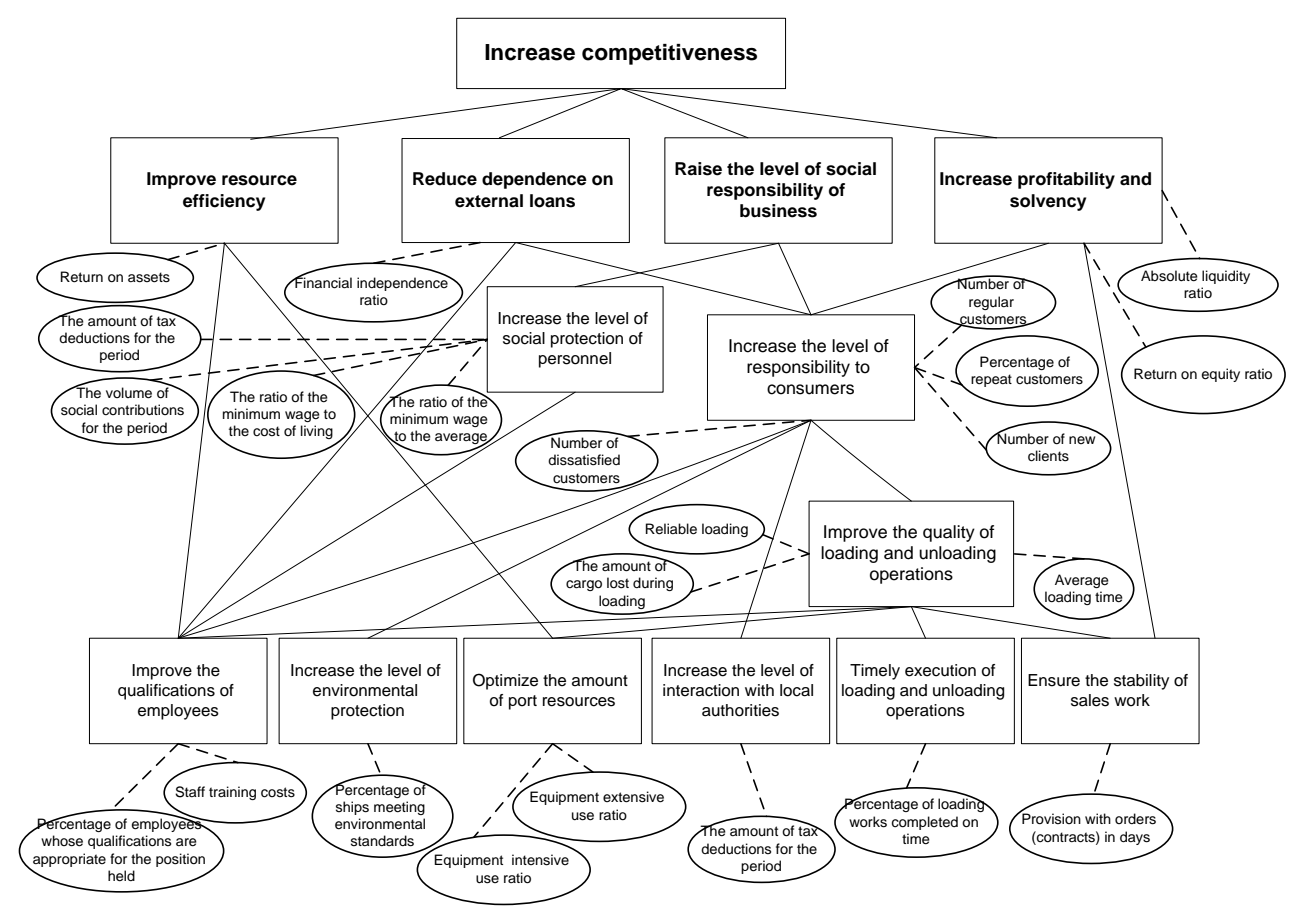

Fig. 1. Tree of cargo port goals with factors for assessing their achievement.

Objects-targets are components of Gccp: GN1 - to reduce dependence on external loans, GN2 - to increase resourceefficiency, GN3 - to increase the level of social responsibility of business, GN4 - to increase profitability and solvency. 


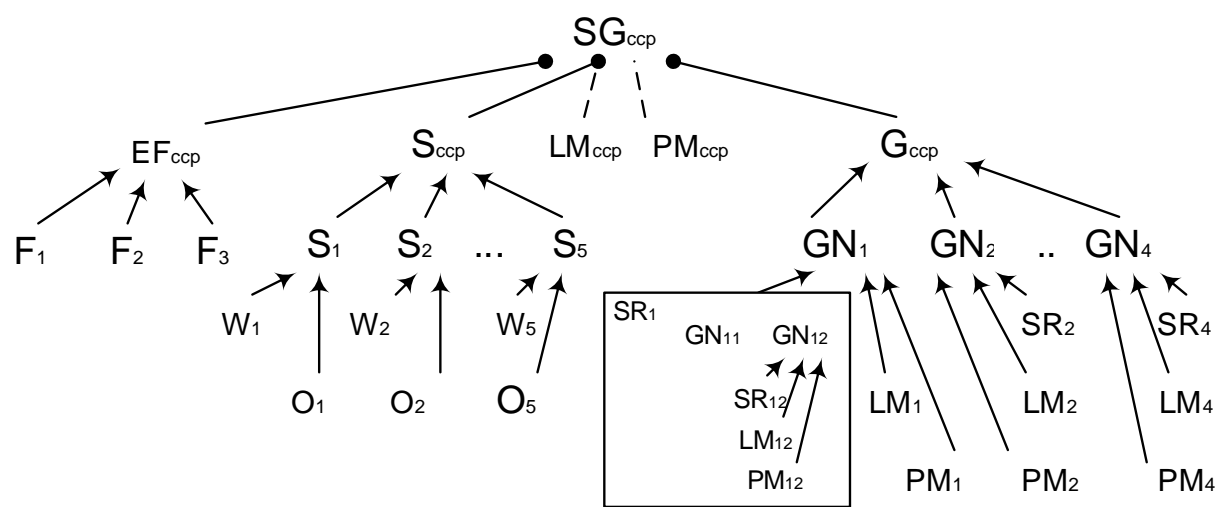

Fig. 2. Multilevel hybrid LP-model of the risk of failure to achieve the strategic goal of the cargo port (detailing the SR1 scenario).

SGccp, Sccp and Gccp are events, S1, S2,.., S5, GN1, GN2,.., GN4 are the corresponding L-variables, F1, F2 and F3 are external random factors of influence. For the functioning of the cargo port, meteorological factors are primarily important: freeze-up, wind speed above 15 meters per second and the presence of fog, respectively. In the failure risk model for solving this complex problem, the scenario of the failure of the SGccp problem is formulated as follows: the failure of the SGccp event occurs due to the failure of the Sccp events AND (logical) of the Gccp events AND (logical) of the EFccp events.

The increased risk of not achieving the main strategic goal of the cargo port is due to failure to achieve any one goal, OR due to failure to achieve any two goals, ... OR due to failure to achieve all goals.

In this case, the logical functions (L-model) of failure of events take the form (LMccp):

$$
S G_{c c p}=S_{c c p} \wedge G_{c c p} \wedge E F_{c c p} ; S_{c c p}=S_{1} \vee S_{2} \vee \ldots \vee S_{5} ; G_{c c p}=G N_{1} \vee G N_{2} \vee \ldots \vee G N_{4}
$$

The probability functions (P-model) of failure of events (PMccp):

$$
\begin{gathered}
P\left\{S G_{c c p}=0\right\}=P\left\{S_{c c p}=0\right\}+P\left\{G_{c c p}=0\right\}\left(1-P\left\{S_{c c p}=0\right\}\right)+P\left\{E F_{c c p}=0\right\} \times \\
\quad \times\left(1-P\left\{S_{c c p}=0\right\}\right)\left(1-P\left\{G_{c c p}=0\right\}\right) ; \\
P\left\{S_{c c p}=0\right\}=P\left\{S_{1}=0\right\}+P\left\{S_{2}=0\right\}\left(1-P\left\{S_{1}=0\right\}\right)+P\left\{S_{3}=0\right\}\left(1-P\left\{S_{1}\right.\right. \\
=0\})\left(1-P\left\{S_{2}=0\right\}\right)+ \\
+P\left\{S_{4}=0\right\}\left(1-P\left\{S_{1}=0\right\}\right)\left(1-P\left\{S_{2}=0\right\}\right)\left(1-P\left\{S_{3}=0\right\}\right)+P\left\{S_{5}=0\right\}\left(1-P\left\{S_{1}\right.\right. \\
=0\}) \times \\
\times\left(1-P\left\{S_{2}=0\right\}\right)\left(1-P\left\{S_{3}=0\right\}\right)\left(1-P\left\{S_{4}=0\right\}\right) ; \\
P\left\{G_{c c p}=0\right\}=P\left\{G N_{1}=0\right\}+P\left\{G N_{2}=0\right\}\left(1-P\left\{G N_{1}=0\right\}\right)+P\left\{G N_{3}=0\right\}\left(1-P\left\{G N_{1}\right.\right. \\
=0\}) \times \quad \\
\times\left(1-P\left\{G N_{2}=0\right\}\right)+P\left\{G N_{4}=0\right\}\left(1-P\left\{G N_{1}=0\right\}\right)\left(1-P\left\{G N_{2}=0\right\}\right)\left(1-P\left\{G N_{3}\right.\right. \\
=0\}) ; \\
P\left\{E F_{c c p}=0\right\}=P\left\{E F_{1}=0\right\}+P\left\{E F_{2}=0\right\}\left(1-P\left\{E F_{1}=0\right\}\right)+P\left\{E F_{3}=0\right\} \times \\
\quad \times\left(1-P\left\{E F_{1}=0\right\}\right)\left(1-P\left\{E F_{2}=0\right\}\right) .
\end{gathered}
$$

The goals GN1, GN2,..., GN4 correspond to the LP risk model. According to the concept of applying hybrid LP risk models for each i-th goal (GNi), it is necessary to sequentially construct a risk scenario (SRi), L-model (LMi) and B-model (PMi).

The above logical and probabilistic models describe the risk at the highest level, the risk of not achieving the strategic goal of the port, and the description and detailing of subjects 
and target objects is essentially a scenario at the upper level. Thus, there is a multilevel LPmodel.

As scenarios of risks of failure to achieve goals GN1, GN2,.., GN4, it is proposed to use elements of the constructed and described above the tree of cargo port goals for a clear understanding of cause-and-effect relationships. Thus, the multi-level structural model is used, each new level of which increases the level of detail for a more detailed elaboration of the issue of risk analysis of the cargo port.

So, for example, for the goal GN1 (to reduce dependence on external borrowing), the detailed goals of the next level are: to improve the skills of employees and increase the level of responsibility to consumers. They are designated by the boolean variables GN11 and GN12, respectively. Based on this, the SR1 scenario is detailed.

Similar reasoning applies to the remaining targets. For target GN2, the detail targets of the next (third) level are the previously described GN11 and GN21 "optimize the number of port resources". For GN3 - GN12, GN1 and GN31 goal is "increase the level of social protection of personnel". Finally, GN4 goal is detailed by GN12 and GN41 "ensure the stability of the distribution business." Thus, based on the scenarios obtained, it is possible to formulate logical functions (L-models) of failure of second-level events, i.e. failure to achieve goals GN1, GN2,.., GN4 (LM1, LM2,.., LM4, respectively):

$$
G N_{1}=G N_{11} \vee G N_{12} ; G N_{2}=G N_{11} \vee G N_{21} ; G N_{3}=G N_{12} \vee G N_{31} ; G N_{4}=G N_{12} \vee G N_{41}
$$

The probability functions (P-models) of failure of the same events (PM1, PM2,.., PM4, respectively):

$$
\begin{aligned}
& P\left\{G N_{1}=0\right\}=P\left\{G N_{11}=0\right\}+P\left\{G N_{12}=0\right\}\left(1-P\left\{G N_{11}=0\right\}\right) ; \\
& P\left\{G N_{2}=0\right\}=P\left\{G N_{11}=0\right\}+P\left\{G N_{21}=0\right\}\left(1-P\left\{G N_{11}=0\right\}\right) ; \\
& P\left\{G N_{3}=0\right\}=P\left\{G N_{12}=0\right\}+P\left\{G N_{31}=0\right\}\left(1-P\left\{G N_{12}=0\right\}\right) ; \\
& P\left\{G N_{4}=0\right\}=P\left\{G N_{12}=0\right\}+P\left\{G N_{41}=0\right\}\left(1-P\left\{G N_{12}=0\right\}\right) .
\end{aligned}
$$

Based on the obtained expressions, let us concretize and expand the probabilistic function of not achieving the strategic goal of the port, introducing the goals of the third level into it. After simplification and reduction of similar ones in $\mathrm{P}\{\mathrm{GN} 12=0\}$, we obtain the following expression:

$$
\begin{gathered}
P\left\{G_{c c p}=0\right\}=P\left\{G N_{11}=0\right\}-\left(P\left\{G N_{11}=0\right\}-1\right)\left[P\left\{G N_{12}=0\right\}+\left(P \left\{G N_{12}\right.\right.\right. \\
=0\}-1)\left[P\left\{G N_{11}=0\right\} \times\right. \\
\times\left(P\left\{G N_{11}=0\right\}-1\right)\left[P\left\{G N_{21}=0\right\}+P\left\{G N_{31}=0\right\}-\left(P\left\{G N_{31}=0\right\}-1\right) P\left\{G N_{12}\right.\right. \\
=0\}]+ \\
+\left(P\left\{G N_{22}=0\right\}-1\right)\left(P\left\{G N_{31}=0\right\}-1\right)\left(P\left\{G N_{41}=0\right\}-\left(P\left\{G N_{41}=0\right\}-1\right) P\left\{G N_{12}\right.\right. \\
=0\}]] .
\end{gathered}
$$

The third level of goal-setting is the decomposition of the GN12 goal into the following: GN11, GN121 - to increase the level of environmental protection, GN122 - to increase the level of interaction with local authorities, GN123 - to improve the quality of loading and unloading operations. All other goals of the third level, being the closing goals of the final levels of detail of the considered individual branches of the goal tree, cannot be supplemented by either the scenario or the LP-model. A diagram of all the scenarios used in this task is shown in Figure 3. 


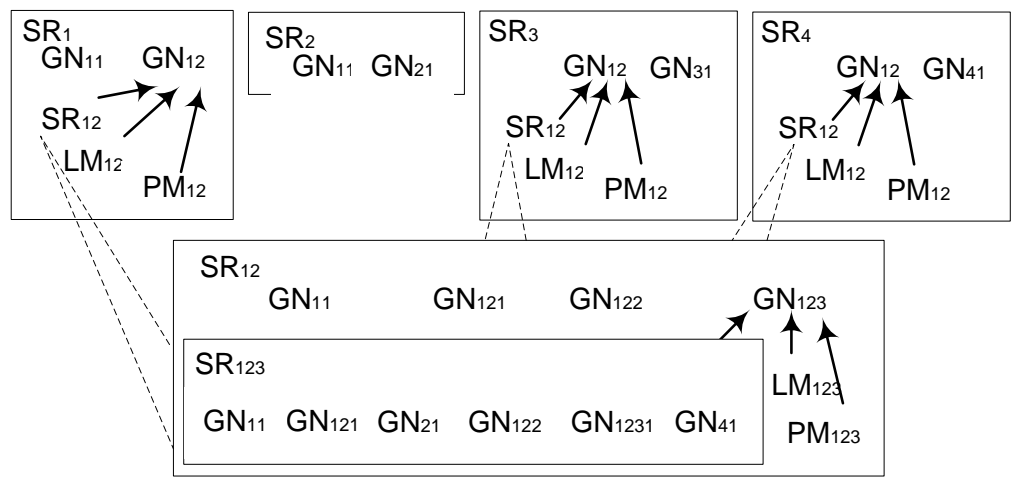

Fig. 3. Model of scenarios of risks of failure to achieve goals associated with the strategic goal of the cargo port.

Based on the scenario of the risk of failure to achieve the goal GN12, we formulate the logical functions (L-models) of failure of this third level event, i.e. LM12:

$$
G N_{12}=G N_{11} \vee G N_{121} \vee G N_{122} \vee G N_{123} \text {. }
$$

The probability function (P-model) PM12 of failure of the goal achievement event $\mathrm{GN}_{12}$ :

$$
\begin{aligned}
& P\left\{G N_{12}=0\right\}=P\left\{G N_{11}=0\right\}+P\left\{G N_{121}=0\right\}\left(1-P\left\{G N_{11}=0\right\}\right)+P\left\{G N_{122}\right. \\
& \quad=0\}\left(1-P\left\{G N_{11}=0\right\}\right) \times \\
& \quad \times\left(1-P\left\{G N_{121}=0\right\}\right)+P\left\{G N_{123}=0\right\}\left(1-P\left\{G N_{11}=0\right\}\right)\left(1-P\left\{G N_{121}\right.\right. \\
& \quad=0\})\left(1-P\left\{G N_{122}=0\right\}\right) .
\end{aligned}
$$

The final fourth level of goal setting is the goal decomposition of GN123. Achieving this goal depends on the following goals: GN11, GN121, GN21, GN122, GN1231 - timely completion of loading and unloading operations and GN41.

Logic function LM123 of failure of the goal achievement event GN123:

$$
G N_{123}=G N_{11} \vee G N_{121} \vee G N_{21} \vee G N_{122} \vee G N_{1231} \vee G N_{41}
$$

Corresponding P-model (PM123):

$$
\begin{aligned}
& P\left\{G N_{123}=0\right\}=P\left\{G N_{11}=0\right\}+P\left\{G N_{121}=0\right\}\left(1-P\left\{G N_{11}=0\right\}\right)+P\left\{G N_{21}\right. \\
& =0\}\left(1-P\left\{G N_{11}=0\right\}\right) \times \\
& \quad \times\left(1-P\left\{G N_{121}=0\right\}\right)+P\left\{G N_{122}=0\right\}\left(1-P\left\{G N_{11}=0\right\}\right)\left(1-P\left\{G N_{121}\right.\right. \\
& =0\})\left(1-P\left\{G N_{21}=0\right\}\right)+ \\
& \quad+P\left\{G N_{1231}=0\right\}\left(1-P\left\{G N_{11}=0\right\}\right)\left(1-P\left\{G N_{121}=0\right\}\right)\left(1-P\left\{G N_{21}\right.\right. \\
& =0\})\left(1-P\left\{G N_{122}=0\right\}\right)+P\left\{G N_{41}=0\right\} \times \\
& \left(1-P\left\{G N_{11}=0\right\}\right)\left(1-P\left\{G N_{121}=0\right\}\right)\left(1-P\left\{G N_{21}=0\right\}\right)\left(1-P\left\{G N_{122}\right.\right. \\
& =0\})\left(1-P\left\{G N_{1231}=0\right\}\right) .
\end{aligned}
$$

\section{Tactical control level}

In order to approach in more detail the issue of LP-modeling of the risk of failure to achieve the goal of the cargo port, using the indicators for assessing the achievement of goals, the scenario each goal can be detailed even deeper. If a specific goal is opposed by indicators that evaluate it. Thus, the transition to the next level of management is carried out - tactical.

In contrast to strategic management, the main task of which is to determine the main goals of the development and functioning of the organization in the long term, tactical management answers the question of how exactly the enterprise can achieve the target state according to the strategy. 
Decisions made in tactical control are less subjective since they are based on more objective and complete information. The implementation of tactical management is concretizing, complementary and revealing strategic goals with a greater degree of detail, relate more to the internal problems of the enterprise and have a smaller gap in time. Also, tactical decisions are easier to assess, rank and select the best option, since tactical management is associated with the formation of a system of specific quantitative assessment indicators.

Defined different levels of scenarios for goals: target scenario - scenario by goals (reflects strategic risks, i.e. risks associated with goals at different levels of detail) and factor scenario (reflects tactical risks associated with failure of the indicator (factor) to reach the standard value, approved by an expert).

The factorial scenario is a scenario detailing by goals, based on a tree of cargo port goals, supplemented by factors for assessing the achievement of each of the goals (Figure 1). However, not all port objectives have factors to assess their achievement, i.e. and tactical scenarios, in this case, will not be available for all targets at various levels of detail. Along with the scenarios, in this context of consideration, it is obvious that the models (logical and probabilistic) will also change due to the inclusion of factor parameters. Let us consider the detailing of scenarios, namely, scenarios by indicators of assessing the achievement of goals, presenting a multi-level cascade hybrid LP-model of the risk of failure to achieve the strategic goal of a cargo port (Figure 4). In this case, cascades represent different levels of detail, corresponding to two levels of control with different degrees of abstraction.

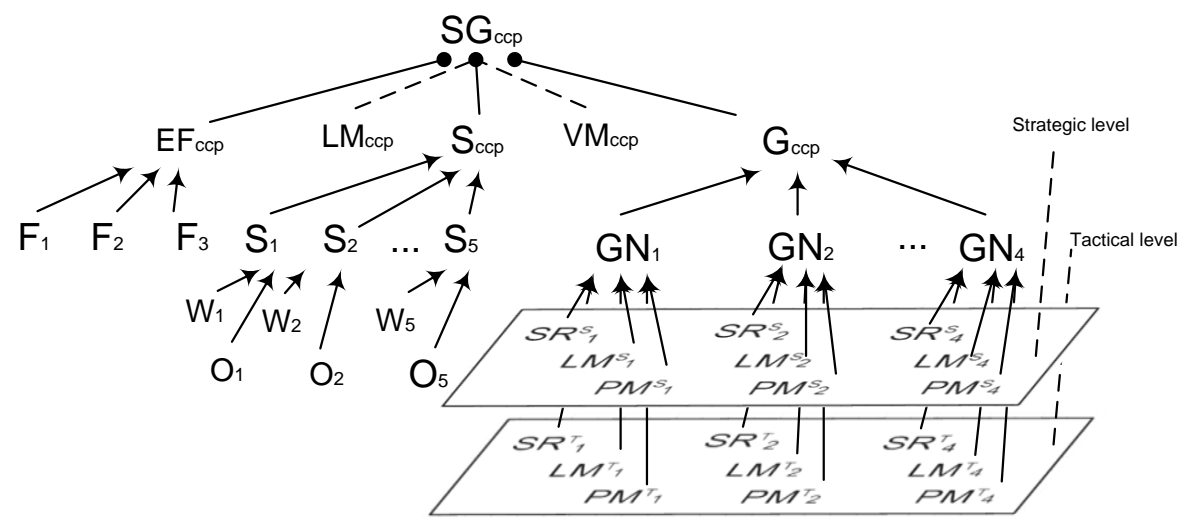

Fig. 4. Multilevel cascade hybrid LP-model of the risk of failure to achieve the strategic goal of the cargo port.

In the transition from the strategic level (the level of goals) to the tactical (level of indicators for assessing the achievement of goals), we detail the L-model. At the tactical level, the failure of an event (goal achievement) may be evidenced by the failure of a certain indicator (or indicators) to reach the normative value. Thus, the following formulation appears: an increase in the risk of failure to achieve the main strategic goal of the cargo port occurs due to the failure of anyone indicator to assess the achievement of this goal of the standard value, OR due to the failure of any two indicators to reach the standard values, ... OR due to the failure of all indicators to reach the standard values. If the goal has estimated indicators at the same level of goal setting, the probability of failure of the event (achievement of the goal) can be replaced by the probability of failure of the indicator characterizing the achievement of this goal to reach the standard value. At the tactical level, the achievement of the goal can be assessed directly (if the goal has a direct indicator of assessment) and indirectly (if the goal can be specified by other goals that have indicators of assessment or 
other specifying goals with indicators of assessment, etc.). In this case, when formulating each new L-model at the next level of goal-setting, more and more new (clarifying) indicators are added to the model, and already existing indicators are not excluded from the L-model. And this property is a distinctive feature of the L-models of the tactical level from the Lmodels of the strategic level, where, when detailing a specific goal, it was replaced by goals that detail it.

New L-variables, $I_{1}{ }^{1}, I_{1}{ }^{2}, I_{1}{ }^{4}$ and $I_{2}{ }^{4}$, are introduced into consideration for formulating tactical-level scenarios for targets GN1, GN2 and GN4. The upper indicator of these variables corresponds to the lower indicator of the goal, the achievement of which is assessed by this indicator, the lower indicator of the indicator - the number in order (within one goal). Variables, $I_{1}{ }^{1}, I_{1}{ }^{2}, I_{1}{ }^{4}$ and $I_{2}{ }^{4}$ correspond to the following evaluation indicators: capital productivity, financial independence ratio, absolute liquidity ratio and return on equity ratio. As can be seen in Figure 1, target GN3 does not have a direct assessment indicator, therefore, the logical function (L-model) of failure of events (LM Tccp) relative to targets (Gccp) can be interpreted as follows:

$$
G_{c c p}=I_{1}{ }^{1} \vee I_{1}{ }^{2} \vee G N_{3} \vee I_{1}{ }^{4} \vee I_{2}{ }^{4}
$$

The probability function (P-model PM Tccp) of failure of events:

$$
\begin{aligned}
& P\left\{G_{c c p}=0\right\}=P\left\{I_{1}{ }^{1} \neq I_{1_{\text {norm }}}{ }^{1}\right\}+P\left\{I_{1}{ }^{2} \neq I_{1_{\text {norm }}}{ }^{2}\right\}\left(1-P\left\{I_{1}{ }^{1} \neq I_{1_{\text {norm }}}{ }^{1}\right\}\right)+P\left\{G N_{3}\right. \\
& =0\}\left(1-P\left\{I_{1}^{1} \neq I_{1_{\text {norm }}}{ }^{1}\right\}\right) \times \\
& \times\left(1-P\left\{I_{1}{ }^{2} \neq I_{1_{\text {norm }}}{ }^{2}\right\}\right)+P\left\{I_{1}{ }^{4} \neq I_{1_{\text {norm }}}{ }^{4}\right\}\left(1-P\left\{I_{1}{ }^{1} \neq I_{1_{\text {norm }}}{ }^{1}\right\}\right)\left(1-P\left\{I_{1}{ }^{2}\right.\right. \\
& \left.\left.\neq I_{1_{\text {norm }}}{ }^{2}\right\}\right)\left(1-P\left\{G N_{3}=0\right\}\right)+ \\
& +P\left\{I_{2}{ }^{4} \neq I_{2_{\text {norm }}}{ }^{4}\right\}\left(1-P\left\{I_{1}{ }^{1} \neq I_{1_{\text {norm }}}{ }^{1}\right\}\right)\left(1-P\left\{I_{1}{ }^{2} \neq I_{1_{\text {norm }}}{ }^{2}\right\}\right) \times\left(1-P\left\{G N_{3}\right.\right. \\
& =0\})\left(1-P\left\{I_{1}^{4} \neq I_{1_{\text {norm }}}{ }^{4}\right\}\right) \text {. }
\end{aligned}
$$

The expression $P\left\{I_{1}{ }^{1} \neq I_{1_{\text {norm }}}{ }^{1}\right\}$ means the probability that the value of the indicator will not reach the standard value. Consider operating scenarios for GN1-GN4 targets.

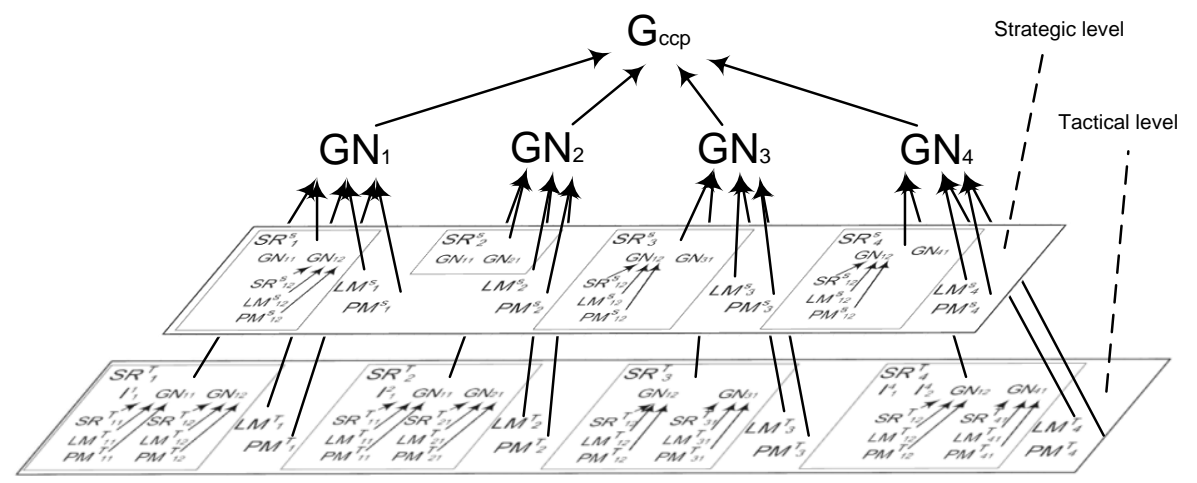

Fig. 5. Cascade LP-model of the risk of failure to achieve the strategic goal of the cargo port (detailing the scenarios of the first level of goal setting).

The tactical level scenario, in addition to the detailed objectives present in the strategic level scenario, also includes indicators for assessing the goal to which this scenario belongs. The indicators used within this formalism are presented in Table 1.

It should be noted that the absence of a scenario at the strategic level for any goal at any level of goal setting does not at all guarantee the absence of a scenario at the tactical level either. So, for example, at the strategic level, the GN11 goal does not have its continuation 
in the form of a scenario (Figure 5), however, at the tactical level, detailing the same goal is realized by the scenario, since this goal can be assessed by two indicators (Figure 6).

Table 1. Indicators for assessing the achievement of port objectives.

\begin{tabular}{|c|c|c|}
\hline $\begin{array}{l}\text { Indicator } \\
\text { designation }\end{array}$ & Index, units & Formula / Method of calculation \\
\hline$I_{1}{ }^{1}$ & Return on assets & $\begin{array}{l}\left.R O A=\frac{S C}{F A V_{a v a}} S C-\text { service cost (period } \mathrm{T}\right), F A V_{a v \cdot a}-\text { average } \\
\text { annual value of fixed assets at the beginning of the year }\end{array}$ \\
\hline$I_{2}{ }^{1}$ & $\begin{array}{l}\text { Financial independence } \\
\text { ratio }\end{array}$ & $F I=\frac{O F}{T A}, O F-$ own funds (capital) in period $\mathrm{T}, T A-$ total assets \\
\hline$I_{1}^{4}$ & Absolute liquidity ratio & $\begin{array}{l}R_{a l}=\frac{O F+F I_{\text {short-term }}}{C L} O F-\text { own funds (capital) in period } \mathrm{T} \text {, } \\
F I_{\text {short-term }}-\text { short-term financial investments, } C L-\text { current } \\
\text { liabilities }\end{array}$ \\
\hline$I_{2}^{4}$ & Return on equity ratio & $\begin{array}{l}R_{r e}=\frac{N P}{O F}, \text { где } N P-\text { net profit for the time period } \mathrm{T}, O F-\text { own funds } \\
\text { (capital) in period T }\end{array}$ \\
\hline$I_{1}{ }^{11}$ & $\begin{array}{l}\text { Percentage of } \\
\text { employees whose } \\
\text { qualifications } \\
\text { correspond to the } \\
\text { position held, } \% \\
\end{array}$ & $\begin{array}{l}P Q E=\frac{N W_{\text {ontime }}}{N W_{\text {total }}} \times 100 N W_{\text {ontime }}-\text { the number of works carried out } \\
\text { during } \mathrm{T} \text {, performed without violating the terms of their } \\
\text { implementation, } N W_{\text {total }}-\text { total number of works performed during } \\
\mathrm{T}\end{array}$ \\
\hline$I_{2}^{11}$ & Staff training costs, rub & $\begin{array}{l}\text { The total cost of the qualification training of employees of the } \\
\text { enterprise }\end{array}$ \\
\hline$I_{1}^{12}$ & $\begin{array}{l}\text { Number of regular } \\
\text { customers, units }\end{array}$ & The number of clients who applied more than twice \\
\hline$I_{2}{ }^{12}$ & $\begin{array}{l}\text { The percentage of } \\
\text { customers who have } \\
\text { applied again, } \%\end{array}$ & $\begin{array}{l}P e r s C_{r e}=\frac{N C_{r e}}{N C_{t o t a l}} \times 100 \%, N C_{r e}-\text { number of customers who re- } \\
\text { applied for a period of time T, } N C_{\text {total }} \text { - the total number of customers } \\
\text { who applied for the period T }\end{array}$ \\
\hline$I_{3}^{12}$ & $\begin{array}{l}\text { Number of new } \\
\text { customers, units }\end{array}$ & The number of new customers during the period $\mathrm{T}$ \\
\hline$I_{4}^{12}$ & $\begin{array}{l}\text { Number of dissatisfied } \\
\text { customers, units }\end{array}$ & $\begin{array}{l}\text { The number of customerswho remained unsatisfied with the services } \\
\text { provided to them for the period T }\end{array}$ \\
\hline$I_{1}{ }^{21}$ & $\begin{array}{l}\text { Equipment intensive } \\
\text { use ratio }\end{array}$ & $\begin{array}{l}E U R \frac{P r_{\text {actual }}}{P r_{\text {tech }}} \text { int }, P r_{\text {actual }}-\text { actual productivity of the main } \\
\text { technological equipment (product units/hour), } P r_{\text {tech }}-\text { technically } \\
\text { justified the productivity of machines and equipment (product } \\
\text { units/hour) }\end{array}$ \\
\hline$I_{2}{ }^{21}$ & $\begin{array}{l}\text { Equipment extensive } \\
\text { use ratio }\end{array}$ & $\begin{array}{l}E U R_{\text {ext }}=\frac{T O_{\text {actual }}}{O T F}, T O_{\text {actual }} \text { - time of actual operation of machines } \\
\text { and equipment, } \mathrm{h}, O T F-\text { operating time fund of machines and } \\
\text { equipment, } \mathrm{h}\end{array}$ \\
\hline$I_{1}^{31}$ & $\begin{array}{l}\text { The number of tax } \\
\text { deductions for the } \\
\text { period, rubles }\end{array}$ & Tax deductions for the period $\mathrm{T}$ are summed up \\
\hline$I_{2}^{31}$ & $\begin{array}{l}\text { The volume of social } \\
\text { contributions for the } \\
\text { period }\end{array}$ & Social contributions for the period $\mathrm{T}$ are summed up \\
\hline$I_{3}{ }^{31}$ & $\begin{array}{l}\text { The ratio of the } \\
\text { minimum wage to the } \\
\text { cost of living }\end{array}$ & $\begin{array}{l}R_{L W a g e}=\frac{\text { Wage }_{\min }}{\text { LWage }} \text { Wage }_{\min }-\text { the size of the minimum wage for } \\
\text { cargo port employees, LWage the officially established size of the } \\
\text { living wage for the region in which the cargo port is located }\end{array}$ \\
\hline$I_{4}{ }^{31}$ & $\begin{array}{l}\text { The ratio of the } \\
\text { minimum wage to the } \\
\text { average, } \%\end{array}$ & $\begin{array}{l}R_{\text {Wage }_{\text {average }}}=\frac{\text { Wage }_{\min }}{\text { Wage }_{\text {average }}} \text { Wag }_{\text {min }}-\text { the size of the minimum wage } \\
\text { for cargo port employees, Wage } \text { average }_{\text {average salary of cargo port }} \\
\text { employees. }\end{array}$ \\
\hline$I_{1}^{41}$ & $\begin{array}{l}\text { Provision with orders } \\
\text { (contracts) in days, } \\
\text { days }\end{array}$ & $\begin{array}{l}O P_{\text {days }}=N C C \times \overline{D_{\text {contract }}}, N C C-\text { number of contracts concluded, } \\
\overline{D_{\text {contract }}}-\text { average duration of work under one contract, days }\end{array}$ \\
\hline$I_{1}^{121}$ & $\begin{array}{l}\text { Share of ships that } \\
\text { meet environmental } \\
\text { standards, } \%\end{array}$ & $\begin{array}{l}E S=\frac{N E S}{N S} \times 100 \%, N S-\text { the total number of ships that used the port } \\
\text { berths during the period T, NES - the number of ships that used the } \\
\text { port berths during the period T, fully complying with environmental } \\
\text { standards }\end{array}$ \\
\hline
\end{tabular}




\begin{tabular}{|c|c|l|}
\hline$I_{1}{ }^{123}$ & $\begin{array}{c}\text { Reliability of } \\
\text { loading, } \%\end{array}$ & $\begin{array}{l}R L=\frac{A A N}{R A N} \times 100 \%, A A N-\text { the number of accepted applications for } \\
\text { the period T, } R A N-\text { the number of applications received during the } \\
\text { same period T }\end{array}$ \\
\hline$I_{2}{ }^{123}$ & $\begin{array}{c}\text { Amount of lost } \\
\text { (damaged) during } \\
\text { loading of cargo, th }\end{array}$ & $\begin{array}{l}Q C_{\text {lost }}=Q C_{\text {plan }}-Q C_{\text {actual }}, Q C_{\text {plan }}-\text { the total quantity (in) of the } \\
\text { cargo, which, according to the accepted applications, was planned to } \\
\text { be shipped within the period T, } Q C_{\text {actual }} \text { - the total number of goods } \\
\text { (tn) actually loaded for T }\end{array}$ \\
\hline$I_{3}{ }^{123}$ & $\begin{array}{c}\text { Average loading time, } \\
\mathrm{h}\end{array}$ & $\begin{array}{l}L T_{\text {average }}=\frac{L T_{\text {total }}}{N E O_{\text {total }}} L T_{\text {total }} \text { - loading time total, } N E O_{\text {total }} \text { total } \\
\text { number of orders executed during the time period T }\end{array}$ \\
\hline$I_{1}{ }^{1231}$ & $\begin{array}{c}\text { Percentage of loading } \\
\text { works completed on } \\
\text { time, } \%\end{array}$ & $\begin{array}{l}\text { PL } \\
\text { during the period T, performed without violating the terms of their } \\
\text { implementation, } N W_{\text {total }} \text { total number of works performed during T }\end{array}$ \\
\hline
\end{tabular}

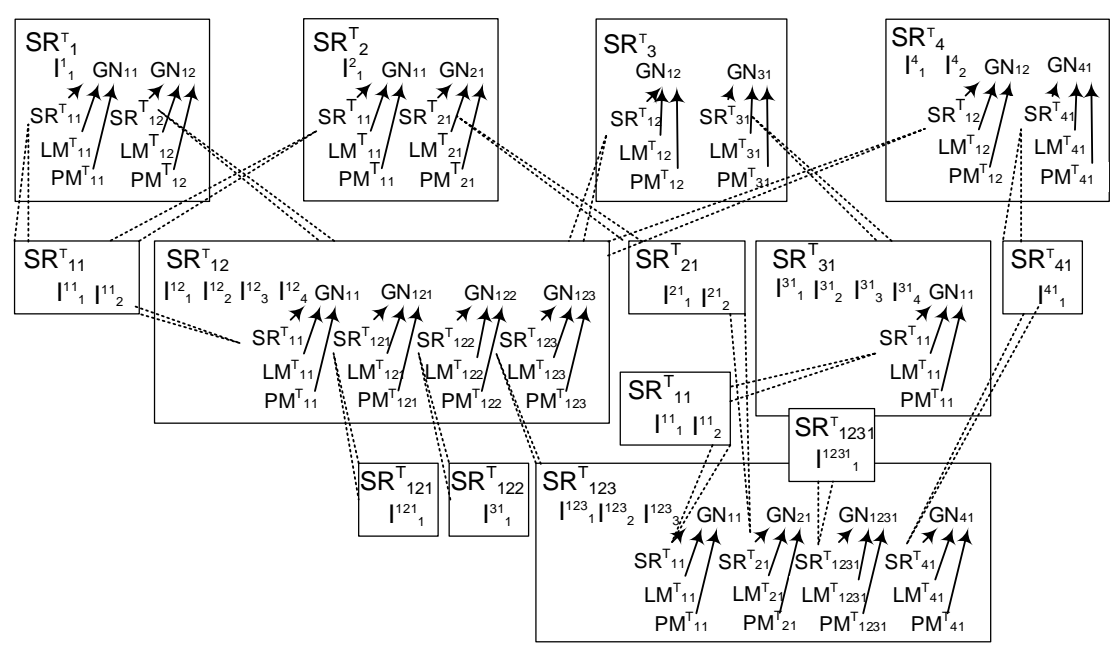

Fig. 6. Model of tactical scenarios of risks of failure to achieve goals associated with the main strategic goal of the cargo port.

Comparison of the strategic and tactical levels scenarios confirms the statement about their characteristic distinctive feature: at the tactical level, there is no detailing of indicators, in contrast to goals, since subgoals concretize the goal, as well as the indicators, concretize not a separate indicator, but a specific goal (assessment of its achievement).

Based on the constructed model of tactical scenarios of risks of failure to achieve goals associated with the main strategic goal of the cargo port, we will formulate logical and probabilistic functions (L- and B-models) of failure of events relative to the goals of the second level of goal setting (GN1, GN2, GN3 и GN4).

$$
\begin{gathered}
\mathrm{LM}^{\mathrm{T}}{ }_{1}: G N_{1}=I_{1}{ }^{1} \vee G N_{11} \vee G N_{12} . \\
\mathrm{VM}^{\mathrm{T}}{ }_{1}: P\left\{G N_{1}=0\right\}=P\left\{I_{1}{ }^{1} \neq I_{1_{\text {norm }}}{ }^{1}\right\}+P\left\{G N_{11}=0\right\}\left(1-P\left\{I_{1}{ }^{1} \neq I_{1_{\text {norm }}}{ }^{1}\right\}\right)+ \\
+P\left\{G N_{12}=0\right\}\left(1-P\left\{I_{1}{ }^{1} \neq I_{1_{\text {norm }}}{ }^{1}\right\}\right)\left(1-P\left\{G N_{11}=0\right\}\right) .
\end{gathered}
$$

The rest of the L- and P-models of the tactical level of management are formulated similarly. 


\section{Results}

The constructed LP-models of the risk of not achieving the strategic goal of the cargo port and the formulated logical and probabilistic models describe the relationship of events - risk situations, which is both input information for the developed simulation model (Figures 78 ), and a toolkit for interpreting the results of experiments with the simulation model.
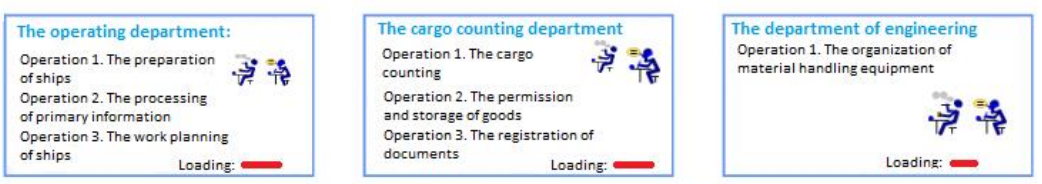

The indicators

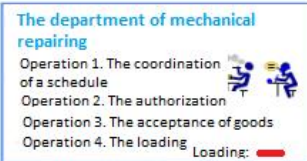

Animation $\mid \underline{\text { The logic of business processes }}$
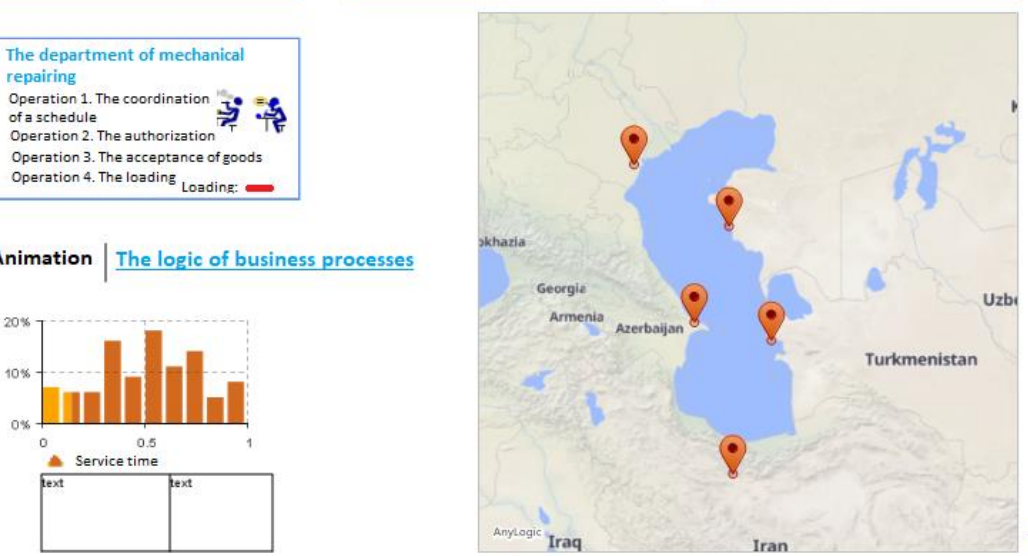

Fig. 7. The simulation model of risk assessment of a cargo port.

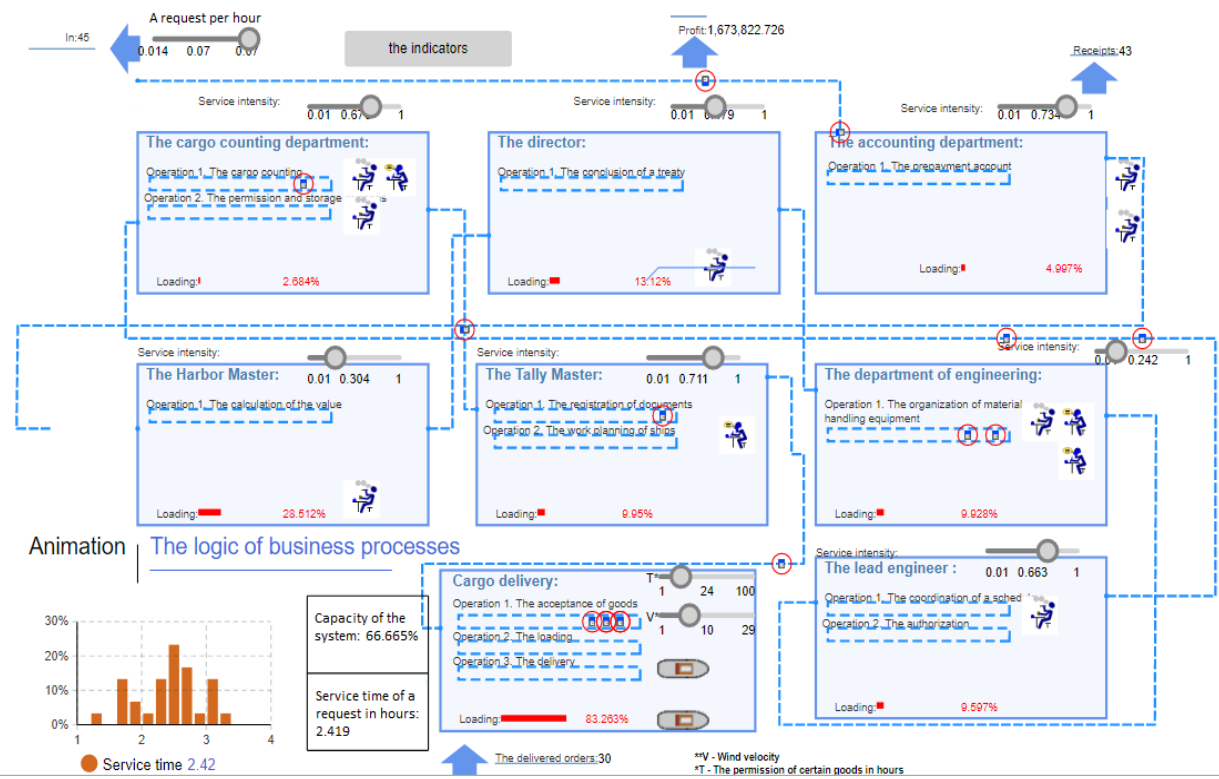

Fig. 8. The simulation model of risk assessment of a cargo port (Animation in dynamics). 
Combining the principles of logical-probabilistic and simulation modeling, namely the possibility of implementing a certain "game" with the parameters of the simulation model - adjusting the input parameters, coupled with a detailed study of the logical and probabilistic relationships of individual port goals, making it possible to obtain a reasonable assessment of the risk of failure to achieve the strategic goal and use it in as a basis for making specific management decisions

\section{Conclusion}

Based on the results of the formulated research goal and the set task, a hybrid logicalprobabilistic model of the risk of failure to achieve the strategic goal of the cargo port was developed, taking into account the use of simulation modeling as an assessment tool, and also formulated a logical and probabilistic model, taking into account the influence of external random factors on the port. These models together represent a toolkit and a mechanism that allows to comprehensively assess the likelihood of risk situations in the port, interpret the results of simulation modeling and identify possible causes of undesirable events to eliminate and prevent them, which means they will increase management efficiency through the formation of well-grounded management decision.

\section{References}

1. Solozhentsev E 2015 International Journal of Risk Assessment and Management 18 (3/4) 237

2. Solozhentsev E, Mityagin S 2015 International Journal of Risk Assessment and Management 18(1) 1

3. Protalinsky O M, Khanova A A, Bondareva I O 2010 Vestnik of Saratov state technical university 4 (50) 134

4. Ramírez-Nafarrate A, González-Ramírez R G, Smith N R 2017Ann Oper Res 258195

5. Vyatskova N A 2015 Problems of Economics and Management 9(49) 15

6. Karasev V V, Solozhentsev E D 2016 Transactions of SPIIRAS 5(48) 124

7. Antokhina Yu A, Baranov A V 2014 News of St. Petersburg State University of Economics 5(89) 55

8. Bayramukova E I 2008 The use of simulation modeling in risk assessment and optimization of management processes in industrial enterprises $\mathbf{8 5} 315$

9. Grigoriev O V, Bondareva I O, Latypova E A 2013 Management, computer engineering and informatics 1155

10. Grigoriev O V, Bondareva I O, Latypova E A 2015 Management, computer engineering and computer science 190 